\title{
Examination of main lymph node (No.253) metastasis in left colorectal cancer: A retrospective analysis of a single- institution cohort
}

Takefumi Yoshida ( $\nabla$ yoshida_takefumi@med.kurume-u.ac.jp )

Kurume University of Medicine

Fumihiko Fujita

Kurume University of Medicine

Dai Shida

The University of Tokyo

Kenichi Koushi

Kurume University of Medicine

Kenji Fujiyoshi

Kurume University of Medicine

Tomoya Sudou

Kurume University of Medicine

Sachiko Nagasu

Kurume University of Medicine

\section{Suguru Ogata}

Kurume University of Medicine

Takashi Noguchi

Kurume University of Medicine

Junya Fukuda

Kurume University of Medicine

Fumiki Koga

Kurume University of Medicine

Maako Kikuchi

Kurume University of Medicine

Yoshito Akagi

Kurume University of Medicine

\section{Research Article}

Keywords: No.253 lymph nodes, colorectal cancer, D3 dissection

Posted Date: October 29th, 2021

DOI: https://doi.org/10.21203/rs.3.rs-1019251/v1

License: (c) (i) This work is licensed under a Creative Commons Attribution 4.0 International License. Read Full License 


\section{Abstract \\ Background.}

The extent of lymph node dissection in advanced colorectal cancer varies according to regional guidelines. D3 lymphadenectomy is routinely performed in Japan but is associated with several risk factors. Metastases of the main lymph nodes (No.253 lymph nodes), which are located at the root of the inferior mesenteric artery, are rare in left-sided colorectal cancer. Tumor depth (T4) is an identifier of No.253 lymph node metastasis (LNM) risk, but other risk factors associated with No.253 LNM are unclear. This study was undertaken to investigate the frequency of No.253 LNM and to identify other clinicopathological risk factors associated with No.253 LNM in left-sided colorectal cancer. In this study, we aimed to evaluate the clinical benefit of routine D3 lymphadenectomy in surgically treated advanced colorectal cancer.

\section{Methods.}

A retrospective database of patients with colorectal cancer who underwent D3 dissection and R0 resection at Kurume University Hospital from 1978 to 2017 was constructed and used to search for the frequency and risk factors of No.253 LNM to investigate long-term prognosis. Clinicopathological factors associated with No.253 LNM, including age, sex, tumor location, T stage, tumor diameter, carcinoembryonic antigen levels, and various dissected lymph nodes, were analyzed.

\section{Results.}

Among 1,614 consecutive patients, No.253 LNM was observed in 23 cases (1.4\%). The presence of three or more regional LNMs was an independent risk factor for No.253 LNM (odds ratio: 26.8). The 5-year overall survival rate was $49.1 \%$ in the No.253 LNM-positive group and $78.4 \%$ in the No.253 LNM-negative group $(p=0.002)$.

\section{Conclusion.}

In left-sided colorectal cancer, No.253 LNM was a poor prognosis factor, and three or more regional LNMs were a risk factor for No.253 LNM. The No.253 LNM-positive group had a poor prognosis, but there are cases of long-term survival, with a 5-year survival rate of $49 \%$. D3 lymphadenectomy is suitable when three or more metastatic LNs are identified prior to surgery.

\section{Background}

The number of deaths from colorectal cancer is highest among all carcinomas in Europe, the United States, and Japan due to changes in diet and lifestyle, and the number of patients diagnosed with colorectal cancer reached 51,420 cases (second among all cancers in Japan) in 2019 [1, 2]. Among these cases, lymph node metastasis (LNM) is an important predictor of patient prognosis [3, 4], and while radical lymph node (LN) dissection has markedly improved survival, the extent of intraoperative regional $L N$ dissection remains a controversial issue.

In Japan, D3 lymphadenectomy is routinely performed in advanced colorectal cancer and involves the removal of the main LNs adjacent to the stem of the feeder artery in addition to D2 lymphadenectomy [4]. In some patients, D3 lymphadenectomy improves prognosis, but the procedure increases the difficulty of the surgery as well as the risk of 
perioperative complication [7-9]. Thus, the indication of D3 lymphadenectomy should be well considered to manifest the true survival benefit.

The Japanese classification uses a three-digit system over 200 to denote the LNs of the large intestine [4]. The No.253 LNs, also known as the main LNs, are regional LNs that are located at the root of the inferior mesenteric artery (Fig. 1) and are resected during routine D3 lymphadenectomy. They represent the third station of lymphatic drainage for rectal cancer, with a metastasis rate of $0.3-11.1 \%$ [10-12]. Thus, this relatively low rate of metastasis questions the oncological benefit of D3 dissection. However, systemic metastasis is thought to originate from the No.253 LNs [7]. In addition, No.253 LNM has been proposed as an independent risk factor for the poor prognosis of colorectal cancer patients [3,13-15]. Further analysis of the risk factors of No.253 LNM would enable better selection of D3 lymphadenectomy in left-side colorectal cancer. Several studies identified age, male sex, tumor size, T stage, degree of differentiation, preoperative tumor markers, tumor wall depth T3/T4, lymphatic invasion, and lateral LNM as important factors affecting LNM at the root of the mesenteric vessel $[8,13,16,17]$.

This study investigated the frequency of No.253 LNM as well as associated risk factors in surgically treated left-side colorectal cancer. We aimed to determine the prognostic significance of No.253 LNM and to identify the associated factors of No.253 LNM in left-sided advanced colorectal cancer patients for the evaluation of the benefit of D3 lymphadenectomy.

\section{Methods}

\section{Patients}

We retrospectively investigated the long-term outcomes of patients with primary colorectal cancer referred to Kurume University Hospital from November 1974 to March 2017. The inclusion criteria were R0 resection (negative margins) and D3 LN dissection. Patients with concurrent malignancies, multiple colorectal cancers, or a histological diagnosis other than adenocarcinoma (squamous cell carcinoma), or who had undergone R1 and R2 resection (residual tumor) or D0-2 LN dissection were excluded. This study was approved by the institutional review board (IRB) of Kurume University Hospital (IRB code: 20254) and complied with our government agency's guidelines. Patient consent to participate in this study was waived because of the retrospective design.

\section{Criteria for D3 lymph node resection}

Preoperative examination confirmed deeper than cT2 invasion, and D3 LN dissection was performed to select patients for $\mathrm{RO}$ resection.

\section{Data collection}

Assessed parameters were age, sex, body mass index, carcinoembryonic antigen (CEA), year of surgery, tumor site, tumor diameter, number of retrieved LNs, category, number of metastatic LNs, No.253 LNs, TNM stage, neuropathy, adjuvant therapy, tumor grade, lymphatic invasion, venous invasion, perineural invasion, surgery time, intraoperative bleeding, and postoperative complications. The extent of primary tumor invasion ( $T$ ), extent of regional LNM (N), and tumor stage were assessed by the Union for International Cancer Control tumor node metastasis (UICC TNM) classification system (8th edition)[7].

\section{Follow-up}

Postoperative follow-up was conducted with measurements of serum tumor markers every 3 months for the first 3 years, then every 6 months for the following 2 years; hepatic imaging [ultrasonography or computed tomography (CT)] and chest X-rays were checked every 3-6 months, and colonoscopy was performed once every year for 5 years. Follow- 
up data were recorded prospectively until patient death or the study cut-off date of August 2018. Complete follow-up was conducted for the entire patient cohort, with a median follow-up time of 60 months (range, 1-341 months) for survivors.

\section{Statistical analysis}

Continuous and categorical variables were compared using the Mann-Whitney $U$ test and the chi-squared test or Fisher's exact test, respectively. Logistic regression analysis for the risk factors of No.253 LNM was performed using age, sex, body mass index, CEA, surgery year, tumor site, tumor diameter, T category, number of metastatic LNs, TNM stage, neuropathy, adjuvant therapy, tumor grade, lymphatic invasion, venous invasion, perineural invasion, surgery time, intraoperative bleeding, and postoperative complications. The extent of primary tumor invasion $(T)$, extent of regional lymph node metastasis (N), and disease-free survival (DFS) after primary surgery was examined in the entire study population, and overall survival (OS) after recurrence was assessed only in patients with recurrence. Survival curves were generated using the Kaplan-Meier method to estimate DFS and OS with the log-rank test. DFS was defined as the interval between the date of primary surgery and the date of recurrence or death from all causes. OS was defined as the interval between the date of primary surgery and the date of death from all causes. Patients alive at the end of the follow-up period were censored. Multivariate Cox proportional hazards regression models were subsequently used to evaluate factors independently associated with recurrence and death. P-values less than 0.05 were considered statistically significant. All statistical analyses were performed using JMP statistical software version 14 (SAS Institute Inc., Cary, NC, USA) and EZR (Saitama Medical Center, Jichi Medical University, Saitama, Japan), a graphical user interface for R (The R Foundation for Statistical Computing, Vienna, Austria).

\section{Results}

\section{Clinicopathological characteristics}

A total of 3,029 patients with primary colorectal cancer (splenic flexure to rectal cancer) were referred to Kurume University Hospital from November 1974 to March 2017. Among these patients, 1,948 met the inclusion criteria. In total, 360 cases were excluded from the investigated cohort because R0 resection could not be performed. The final study population consisted of 1,614 patients (Fig. 2). Among these patients, 23 cases (1.4\%) had No.253 LNM.

Patients' characteristics are shown in Table 1. Patients' median age was 64 years (range, 16-92 years), and 1,014 patients (63\%) were men and 600 (37\%) were women. No significant differences were identified between No.253 LNMpositive and No.253 LNM-negative patients in terms of sex, BMI, CEA levels, year of surgery, tumor site, tumor diameter, number of retrieved nodes, adjuvant therapy, or perineural invasion. A univariate analysis revealed that age, $T$ category, number of metastatic LNs, TNM stage, neuropathy, tumor grade, lymphatic invasion, and venous invasion were associated with No.253 LNM (Table 1). Multivariate analysis demonstrated that three or more metastatic LNs was an independent predictor of No.253 LNM positivity (odds ratio [OR] 26.816, 95\% confidence interval [CI] 5.839-123.151, $\mathrm{p}<0.0001)$. No other clinicopathological factors were independent predictors for No.253 LNM. To determine independent characteristics associated with No.253 LNM, we identified three or more metastatic LNs (odds ratio (OR) 26.816, 95\% confidence interval (Cl) 5.839-123.151, $p<0.0001$ ) as an independent predictor of No.253 LNM positivity (Table 1). Previous reports identified T4 as a risk factor for No.253 LNM $[4,18]$, but in this study, 20 (\%) of the No.253 LNMpositive group had pT4, but this was not an independent risk factor (OR 2.615, 95\% Cl 0.726-9.420, $p=0.109$ ).

\section{Surgical method}


No.253 LN dissection was performed in all cases; these details are summarized in Table 2. Left-hemicolectomy (LHC) was performed in all splenic flexure cases and $61 \%$ of descending colon cancer cases. Sigmoidectomy was performed in $95 \%$ of cases with sigmoid colon cancer, and anterior resection (AR) was performed in $97 \%$ of cases with rectosigmoid cancer and in $96 \%$ of the cases with upper rectal cancer. For the cases with lower rectal cancer, $39 \%$ of cases were treated with abdominoperineal resection (APR), $35 \%$ of cases with AR, and $24 \%$ of cases with intersphincteric resection (ISR).

\section{Distribution of metastatic lymph nodes in left colorectal cancer}

The distribution of metastatic LNs in left-sided colorectal cancer in this study is summarized in Table 3. No No.253 LNM was observed in cases with tumors located in the splenic flexure or descending colon. In cases with sigmoid colon cancer, LNM was observed in 273 of 498 cases, of which $60.0 \%$ cases had No. 241 LNM and $2.9 \%$ cases had No. 253 LNM. In rectosigmoid cancer, LNM was observed in 159 of 289 cases, of which $67.9 \%$ cases had No.251 LNM and $1.9 \%$ cases No.253 LNM. In cases with upper rectal cancer, LNM was observed in 135 of 255 cases. Of these, $70.4 \%$ had No.251 LNM, 3.0\% had No.253 LNM, and 5.9\% had lateral LNM (LLNM). In cases with lower rectal cancer, LNM was observed in 287 of 505 cases. Of these, $61.3 \%$ had No.251 LNM, 2.8\% had No.253 LNM, and 17.8\% had LLNM.

\section{Univariate and multivariate analyses of risk factors for overall survival}

According to the univariate analysis, no significant associations were identified between tumor site, tumor diameter, perineural invasion, or postoperative complications (Table 4). Multivariate analysis revealed that year of surgery (19952017 [193 months] vs 1974-1994 [180 months]; HR 16.491, 95\% Cl 12.922-21.046, $p<0.0001)$, age (<56 years [337 months] vs $\geq 56$ [170 months]; HR 1.207, 95\% Cl 1.025-1.422, $p=0.024)$, CEA level ( $\leq 5 \mathrm{ng} / \mathrm{ml}$ [210 months] vs $<5 \mathrm{ng} / \mathrm{ml}$ [170 months]; HR 1.176, 95\% Cl 1.003-1.380, $p=0.046)$, surgery length ( $<278$ mins [213 months] vs $\geq 278$ mins [179 months]; HR 1.669, 95\% Cl 1.410-1.976, $p<0.0001)$, intraoperative bleeding volume (<280 ml [229 months] vs $\geq 280$ [175 months]; HR 0.52, 95\% Cl 0.435-0.622, p<0.0001), No.253 LNM (No.253 LNM negativity [200 months] vs No.253 LNM positivity [ 57 months]; HR $0.431,95 \% \mathrm{Cl} 0.187-0.994, p=0.048$ ), lymphatic vessel invasion (no [205 months] vs yes [149 months]; HR 1.255, 95\% Cl 1.023-1.539, $p=0.029$ ), and postoperative adjuvant chemotherapy (yes [212 months] vs no [174 months]; HR $0.84,95 \% \mathrm{Cl} 0.723-0.975, p=0.022$ ) were associated with OS (Table 4).

\section{Recurrence and survival}

To identify the clinical importance of the No.253 LNM in left-side colorectal cancer, OS and DFS were compared between the No.253 LNM-negative group and the No.253 LNM-positive group. As shown in Figure 3, DFS and OS of the No.253 LNM-positive group was significantly worse than that of the No.253 LNM-negative group. Five-year OS rates were $49.1 \%$ in the No.253 LNM-positive group and 78.4\% in the No.253 LNM-negative group, with a median follow-up time of 60 months (range, $1-341$ months) ( $p=0.002$; Fig. 3).

During the follow-up period after radical surgery, tumor recurrence was observed in 329 of 1,614 cases (20\%) in this study. Of the 329 cases, 11 cases (47\%) were in the No.253 LNM-positive group and 318 cases (20\%) were in the No.253 LNM-negative group. $n=11$ (47\%) vs No.253 LNM-negative group $n=318$ (20\%). Especially, lung metastasis was significantly greater in the No.253 LNM-positive group than in the No.253 LNM-negative group (OR 3.765, p=0.013; Table 5). The No.253 LNM-positive group was more likely to have lung metastasis recurrence than the No.253 LNMnegative group (OR 3.765, $p=0.013$; Table 5). 


\section{Discussion}

In this study, we revealed that, among 1,614 patients with left-sided colorectal cancer, the frequency of No.253 LNM was $1.4 \%$ and that an independent risk factor of No.253 LNM was three or more regional LNMs. Indeed, among 307 patients with three or more regional LNMs, No.253 LNM was observed in 6.8\%, which was 4.8 times more than the baseline. We also revealed that the long-term outcomes of No.253 LNM-positive patients were significantly worse than those of No.253 LNM-negative patients, and one of the reasons for the worse prognosis of No.253 LNM-positive patients was a higher frequency of lung metastasis compared with No.253 LNM-negative patients (OR 3.77).

Our univariate analysis identified age, T stage, number of metastatic LNs, TNM stage, neuropathy, tumor grade, lymphatic invasion, and venous invasion as potential risk factors for No.253 LNM. The association of lymphatic invasion with No.253 LNM was previously described [8, 15]. Huh et al. also observed that the T stage was associated with No.253 LNM, whereby the deeper the tumor infiltration of the intestinal wall, the higher the metastasis rate of No.253 LNs [8]. Age was not correlated with No.253 LNM in previous studies [7, 13], and although this finding was not statistically significant in the multivariate analysis, the degree of tumor differentiation in the younger age group is of interest to determine if there is any correlation. Patients with lymphovascular invasion have a higher rate of No.253 LNM [8], as reflected in the univariate analysis in the current study whereby $64.3 \%$ had lymphatic invasion compared with $20.2 \%$ of No.253 LNM-negative patients. Previous studies also reported that pT4 colorectal cancer, in which the tumor has penetrated the visceral peritoneum and/or directly invaded other organs or both, was a risk factor for No.253 LNM [18-20]. Although there were no statistically significant differences in this study, $87 \%$ of the No.253 LNM-positive group consisted of pT4 cases. CEA at the diagnosis level was not a risk factor for No.253 LNM in this study, inconsistent with previous studies indicating that higher preoperative levels of CEA were associated with No.253 LNM $[8,15,21,22]$. This variation might be due to the small number of samples analyzed in these studies.

Multivariate analysis to determine independent characteristics associated with No.253 LNM identified three or more LNMs as an independent predictor of No.253 LNM positivity (OR 26.816, 95\% Cl 5.839-123.151, p<0.0001). Contrary with the result of our study, no significant correlation was identified with the number of harvested LNs with No.253 LNM in a previous report [8]. Hu et al. also reported that No.253 LNM patients harvested more LNs, but this was not significant by multivariate regression analysis. Further investigations in a larger cohort are warranted to confirm this result.

No.253 LNM was previously identified as an independent risk factor affecting the long-term prognosis of patients with colorectal cancer $[7,8,23]$. The current study revealed that patients with No.253 LNM had multiple regional LNMs, but No.253 LNM was not identified in isolation. The 5-year OS rate of patients with and without No.253 LNM was $49.1 \%$ and $78.4 \%$, respectively $(p=0.002)$. Our study found that recurrence after R0 surgery occurred in $20 \%$ of patients, and lung metastasis was an independent risk factor in No.253 LNM-positive patients (OR 3.765, $p=0.013)$. Inferior mesenteric artery LNM was an independent predictive factor for high systemic recurrence [24].

The effect of D3 dissection and D2 dissection on prognosis in colorectal cancer remains controversial [20, 25], and it was reported that the number of removed LNs is significantly higher in D3 dissection [25]. Furthermore, a survival advantage of D3 dissection over D2 dissection in pT3 and pT4 colon cancer was identified [26]. While the UICC TNM classification focuses on absolute numbers of nodal metastases [6], the Japanese Classification of Colorectal Cancer (JSCCR) is based on LN distribution [4]. The latest version of the JSCCR guidelines is more closely aligned with the UICC TNM classification system to achieve a more unified approach to the international tumor staging guidelines [4]. Surgery is the most common treatment approach for colorectal cancer, and the JSCCR guidelines recommend routine D3 lymphadenectomy for advanced colorectal cancer [4]. However, D3 lymphadenectomy may damage the nerves and vessels adjacent to the main LNs that lead to dysuria, sexual dysfunction, and anastomotic leakage due to ischemic 
change [6. 19]. D2 lymphadenectomy has lower surgery-related risks for patients than D3 dissection but possibly a lower oncological outcome. To suppress the recurrence of tumors and minimize the occurrence of complications, it is important to distinguish which cases are suitable for D3 lymphadenectomy. The factor that the number of regional lymph node metastasis is less than 2 is very important as a marker to be reflected in No. 253 LYM in this study. Moreover, the number of removed LNs is a prognostic factor following colorectal cancer surgery, it has been demonstrated that vertical LN dissection is more important than horizontal LN dissection [20, 27, 28 ].

Because main LNM is a poor prognostic factor, as shown in this study, the question remains as to whether main LNM should be screened before or during surgery. Previous reports have identified tumor wall depth as a risk of main LNM [18-20, 25]. In this study, we revealed that No.253 LNM occurs at a higher rate in cases with three or more regional LNM. Thus, D2 dissection may be acceptable if three or more metastatic LNs are not suspected before and during surgery.

There are several limitations to this study. First, it was a single-center retrospective study. Second, in rectal cancer cases, cases with and without lateral LN dissection were mixed. Furthermore, the cases were treated as far back as 1978, and chemotherapy and surgical approaches have improved with time, resulting in variable data; for example, oxaliplatin was approved for advanced colorectal cancer in the 2000s, and the recurrence rate decreased after surgery for colorectal cancer. Finally, we did not examine the concordance rate between preoperative LNM prediction and pathological diagnosis.

\section{Conclusions}

In conclusion, although the frequency of No.253 LNM is low in left-sided colorectal cancer, patients with No.253 LNM have poor long-term prognosis. Accurate preoperative diagnosis of No.253 LNM is required to reduce unnecessary procedures and improve outcome. This study revealed that three or more LNMs is a risk factor for No.253 LNM regardless of the depth of the tumor wall. When three or more metastatic LNs are suspected prior to surgery, it is necessary to perform D3 lymphadectomy.

\section{List Of Abbreviations}

APR, abdominoperineal resection

$\mathrm{AR}$, anterior resection

CEA, carcinoembryonic antigen

$\mathrm{Cl}$, confidence interval

CT, computed tomography

DFS, disease-free survival

HR, hazard ratio

IRB, institutional review board

ISR, intersphincteric resection

JSCCR, Japanese Classification of Colorectal Cancer 
LN, lymph node

LNM, lymph node metastasis

OR, odds ratio

OS, overall survival

TNM, tumor node metastasis

UICC, Union for International Cancer Control

\section{Declarations}

\section{Ethics approval and consent to participate}

This study was approved by the IRB of Kurume University Hospital (IRB code: 20254) and met our governmental agency's guidelines. Patient consent to participate in this study was waived because of the retrospective design.

\section{Consent for publication}

Not applicable.

\section{Availability of data and materials}

Not applicable.

\section{Competing interests}

The authors declare that they have no competing interests.

\section{Funding}

None.

\section{Authors' contributions}

TY conceived and designed the study. KK, SO, JF, FK, and TN performed the data acquisition. SN, KF, and MK contributed to the analysis and interpretation of the data. FF and TS drafted the manuscript. DS and YA critically revised the manuscript for important intellectual content. All authors read and approved the final manuscript.

\section{Acknowledgements}

The authors thank H. Isomoto, K. Shirouzu, and O. Yutaka, former staff members in our division. The authors also thank their colleagues and nurses who provided patient care. Finally, we thank H. Nikki March, PhD, from Edanz (https://jp.edanz.com/ac) for editing a draft of this manuscript.

\section{References}


1. Bray F, Ferlay J, Soerjomataram I, Siegel RL, Torre LA, Jemal A. Global cancer statistics 2018: GLOBOCAN estimates of incidence and mortality worldwide for 36 cancers in 185 countries. CA J Clin. 2018;68:394-424.

2. Cancer Statistics in Japan: [https://ganjoho.jp/reg_stat/statistics/dl/index.html\#mortality] Accessed on $15 / 08 / 2021$.

3. Yeom SS, Lee SY, Kim CH, Kim HR, Kim YJ. The prognostic effect of adjuvant chemotherapy in the colon cancer patients with solitary lymph node metastasis. Int J Colorectal Dis. 2019;34:1483-90.

4. Hashiguchi Y, Muro K, Saito Y, Ito Y, Ajioka Y, Hamaguchi T, et al. Japanese Society for Cancer of the Colon and Rectum (JSCCR) guidelines 2019 for the treatment of colorectal cancer. Int J Clin Oncol. 2020;25:1-42.

5. Japanese Society for Cancer of the Colon and Rectum. Japanese Classification of Colorectal, Appendiceal, and Anal Carcinoma: the 3rd English Edition [Secondary Publication]. J Anus Rectum Colon. 2019;3:175-95.

6. International Union Against Cancer. UICC TNM Classification of Malignant Tumors, 8th edition New York: WileyBlackwell; 2016.

7. Kang J, Hur H, Min BS, Kim NK, Lee KY. Prognostic impact of inferior mesenteric artery lymph node metastasis in colorectal cancer. Ann Surg Oncol. 2011;18:704-10.

8. Huh JW, Kim YJ, Kim HR. Distribution of lymph node metastases is an independent predictor of survival for sigmoid colon and rectal cancer. Ann Surg. 2012;255:70-8.

9. Lee SH, Lee JL, Kim CW, Lee HI, Yu CS, Kim SC. Oncological significance of para-aortic lymph node and inferior mesenteric lymph node metastasis in sigmoid and rectal adenocarcinoma. Eur J Surg Oncol. 2017;43:2076-83.

10. Uehara K, Yamamoto S, Fujita S, Akasu T, Moriya Y. Impact of upward lymph node dissection on survival rates in advanced lower rectal carcinoma. Dig Surg. 2007;24:375-81.

11. Kawamura YJ, Sakuragi M, Togashi K, Okada M, Nagai H, Konishi F. Distribution of lymph node metastasis in T1 sigmoid colon carcinoma: should we ligate the inferior mesenteric artery? Scand J Gastroenterol. 2005;40:858-61.

12. Hida JI, Okuno K. High ligation of the inferior mesenteric artery in rectal cancer surgery. Surg Today. 2013;43:8-19.

13. Yi JW, Lee TG, Lee HS, Heo SC, Jeong SY, Park KJ, et al. Apical-node metastasis in sigmoid colon or rectal cancer: is it a factor that indicates a poor prognosis after high ligation? Int J Colorect Dis. 2012;27(1):81-7.

14. Kim JC, Lee KH, Yu CS, Kim HC, Kim JR, Chang HM, et al. The clinicopathological significance of inferior mesenteric lymph node metastasis in colorectal cancer. Eur J Surg Oncol. 2004; 30: 271-9

15. Hu S, Li S, Teng D, Yan Y, Lin H, Liu B, et al. Analysis of risk factors and prognosis of 253 lymph node metastasis in colorectal cancer patients. BMC Surg. 2021;21:280.

16. Ang CW, Tweedle EM, Campbell F, Rooney PS. Apical-node metastasis independently predicts poor survival in Dukes C colorectal cancer. Colorectal Dis. 2011;13:526-31.

17. Inoue H, Sasaki K, Nozawa H, Kawai K, Murono K, Emoto S, et al. Therapeutic significance of D3 dissection for low rectal cancer: A comparison of dissections between the lateral pelvic lymph nodes and the lymph nodes along the root of the inferior mesenteric artery in a multicenter retrospective cohort study. Int J Colorectal Dis. 2021;36:126370.

18. Kanemitsu Y, Hirai T, Komori K, Kato T. Survival benefit of high ligation of the inferior mesenteric artery in sigmoid colon or rectal cancer surgery. Br J Surg. 2006;93:609-15.

19. Chin CC, Yeh CY, Tang R, Changchien CR, Huang WS, Wang JY. The oncologic benefit of high ligation of the inferior mesenteric artery in the surgical treatment of rectal or sigmoid colon cancer. Int J Colorectal Dis. 2008;23:783-8.

20. Hashiguchi Y, Hase K, Ueno H, Mochizuki H, Shinto E, Yamamoto J. Optimal margins and lymphadenectomy in colonic cancer surgery. Br J Surg 2011;98:1171-8. 
21. Wang XJ, Chi P, Lin HM, Lu, XR, Huang Y, Zu ZB, et al. A scoring system to predict inferior mesenteric artery lymph node metastasis and prognostic value of its involvement in rectal cancer. Int J Colorectal Dis. 2014;29:293-300.

22. Sun Y, Chi P, Lin H, Lu X, Huang Y, Xu Z, et al. Inferior mesenteric artery lymph node metastasis in rectal cancer treated with neoadjuvant chemoradiotherapy: Incidence, prediction and prognostic impact. Eur J Surg Oncol. 2017;43:85-91.

23. Takabatake K, Arita T, Nakanishi M, Kuriu Y, Murayama Y, Shimizu H, et al. Impact of inferior mesenteric artery lymph node metastasis on the prognosis of left-sided colorectal cancer. Anticancer Res. 2021;41:2533-42.

24. Rao X, Zhang J, Liu T, Wu Y, Jiang Y, Wang P, et al. Prognostic value of inferior mesenteric artery lymph node metastasis in cancer of the descending colon, sigmoid colon and rectum. Colorectal Dis. 2018;20:0135-42.

25. Karachun A, Panaiotti L, Chernikovskiy I, Achkasov S, Gevorkyan Y, Savanovich N, et al. Short-term outcomes of a multicentre randomized clinical trial comparing D2 versus D3 lymph node dissection for colonic cancer (COLD trial). Br J Surg 2020;107:499-508.

26. Kotake K, Mizuguchi T, Moritani K, Wada O, Ozawa H, Oki I, et al. Impact of D3 lymph node dissection on survival for patients with T3 and T4 colon cancer. Int J Colorectal Dis. 2014;29:847-52.

27. West NP, Hohenberger W, Weber K, Perrakis A, Finan PJ, Quirke P. Complete mesocolic excision with central vascular ligation produces an oncologically superior specimen compared with standard surgery for carcinoma of the colon. J Clin Oncol. 2010;28:272-8.

28. West NP, Kobayashi H, Takahashi K, Perrakis A, Weber K, Hohenberger W, et al. Understanding optimal colonic cancer surgery: comparison of Japanese D3 resection and European complete mesocolic excision with central vascular ligation. J Clin Oncol. 2012;30:1763-9.

\section{Tables}

Table 1. Association of patients' clinicopathological characteristics with No.253 lymph node metastases 


\begin{tabular}{|c|c|c|c|c|c|c|c|}
\hline Variable & All patients & No & 53 LNM & Univariable & Mult: & variable a & nalysis \\
\hline & $\mathrm{n}=1614$ & $\begin{array}{c}\text { Positive } \\
(\mathrm{n}=23)\end{array}$ & $\begin{array}{l}\text { Negative } \\
(\mathrm{n}=1591)\end{array}$ & $p$-value & $\begin{array}{l}\text { Odds } \\
\text { ratio }\end{array}$ & $95 \%$ CI & $p$-value \\
\hline Age & & & & 0.001 & 2.029 & $\begin{array}{l}0.856- \\
4.811\end{array}$ & 0.108 \\
\hline Median (range) & $64(16-92)$ & $\begin{array}{c}56(29- \\
78)\end{array}$ & $64(16-92)$ & & & & \\
\hline Sex & & & & 1.000 & & & \\
\hline Male/female & $1014 / 600$ & $15 / 8$ & $999 / 592$ & & & & \\
\hline BMI & & & & 0.834 & & & \\
\hline Median (range) & $\begin{array}{c}21.8(13.1- \\
39.3)\end{array}$ & $\begin{array}{l}21.4 \\
(18.1- \\
32.7)\end{array}$ & $\begin{array}{c}21.8(13.1- \\
39.3)\end{array}$ & & & & \\
\hline CEA $(\mathrm{ng} / \mathrm{ml})$ & & & & 0.383 & & & \\
\hline$<5 / \geq 5$ & $1105 / 509$ & $14 / 9$ & $1103 / 488$ & & & & \\
\hline Year of surgery & & & & 0.036 & & & \\
\hline $\begin{array}{l}1974-1995 / 1996- \\
2017\end{array}$ & $639 / 975$ & $14 / 9$ & $625 / 966$ & & & & \\
\hline Tumor site* & & & & 0.982 & & & \\
\hline Left-sided colon & 565 & 8 & 557 & & & & \\
\hline Rectum & 1049 & 15 & 1034 & & & & \\
\hline $\begin{array}{l}\text { Tumor diameter } \\
(\mathrm{mm})\end{array}$ & & & & 0.086 & & & \\
\hline Median (range) & $45(3-170)$ & $\begin{array}{c}55(22- \\
80)\end{array}$ & $45(3-170)$ & & & & \\
\hline T category & & & & $<0.001$ & 2.615 & $\begin{array}{l}0.726- \\
9.420\end{array}$ & 0.109 \\
\hline pT1/pT2/pT3 & $126 / 288 / 382$ & $0 / 1 / 2$ & $126 / 287 / 380$ & & & & \\
\hline pT4 & 818 & 20 & 798 & & & & \\
\hline $\begin{array}{l}\text { No. of retrieved } \\
\text { lymph nodes }\end{array}$ & & & & 0.079 & & & \\
\hline$\geq 12 /<12$ & $1411 / 186$ & $23 / 0$ & $1388 / 186$ & & & & \\
\hline $\begin{array}{l}\text { Number of } \\
\text { metastatic lymph } \\
\text { nodes* }\end{array}$ & & & & $<0.0001$ & 26.816 & $\begin{array}{l}5.839- \\
123.151\end{array}$ & $<0.0001$ \\
\hline$<3 / \geq 3$ & $1307 / 307$ & $2 / 21$ & $1306 / 286$ & & & & \\
\hline TNM stage** & & & & $<0.0001$ & & & \\
\hline $\mathrm{I} / \mathrm{II}$ & $330 / 567$ & $0 / 0$ & $330 / 567$ & & & & \\
\hline III/IV & $658 / 59$ & $16 / 7$ & $642 / 52$ & & & & \\
\hline Neuropathy*** & & & & 0.003 & & & \\
\hline No/yes & $1433 / 181$ & $16 / 7$ & $1417 / 174$ & & & & \\
\hline Adjuvant therapy & & & & 0.151 & & & \\
\hline $\begin{array}{l}\text { Single } \\
\text { agent/doublet }\end{array}$ & $753 / 64$ & $16 / 1$ & $737 / 63$ & & & & \\
\hline None & 610 & 5 & 605 & & & & \\
\hline Tumor grade* & & & & 0.002 & 1.727 & $\begin{array}{l}0.568- \\
5.248\end{array}$ & 0.335 \\
\hline $\mathrm{G} 1, \mathrm{G} 2$ & 1515 & 18 & 1497 & & & & \\
\hline G3 & 99 & 3 & 37 & & & & \\
\hline Lymphatic invasion & & & & $<0.0001$ & 1.956 & $\begin{array}{l}0.748- \\
5.112\end{array}$ & 0.218 \\
\hline No/yes & $1329 / 281$ & $9 / 14$ & $1319 / 267$ & & & & \\
\hline Venous invasion & & & & 0.004 & 0.991 & $\begin{array}{l}0.388- \\
2.531\end{array}$ & 0.984 \\
\hline No/yes & $1365 / 243$ & $14 / 9$ & $1351 / 233$ & & & & \\
\hline Perineural invasion & & & & .343 & & & \\
\hline
\end{tabular}


No/yes $\quad 1412 / 191 \quad 19 / 4 \quad 1393 / 187$

BMI, body mass index; CEA, carcinoembryonic antigen; LNM, lymph node metastasis

*Left-sided colon: splenic flexure to rectosigmoid colon

* 253 lymph node and lateral lymph nodes were not included

**TNM stage: UICC $8^{\text {th }}$, stage IV: Lateral lymph node-positive cases of rectal cancer

***Neuropathy: sexual dysfunction, urination disorder

$*^{*}$ G1, well differentiated; G2, moderately differentiated; G3, poorly differentiated, undifferentiated

Table 2. Types of surgery performed in colorectal cancer cases in this study

\begin{tabular}{|c|c|c|c|c|c|c|c|c|}
\hline 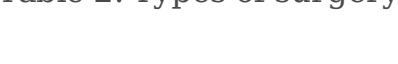 & PC & $\mathrm{LHC}$ & S & $\mathrm{AR}$ & ISR & APR & $\mathrm{H}$ & TPE \\
\hline Splenic flexure $\mathrm{n}=11$ & & $\begin{array}{c}11 \\
(100 \%)\end{array}$ & & & & & & \\
\hline $\begin{array}{l}\text { Descending colon } \\
\mathrm{n}=56\end{array}$ & $\begin{array}{c}22 \\
(39 \%)\end{array}$ & $34(61 \%)$ & & & & & & \\
\hline $\begin{array}{l}\text { Sigmoid colon } \\
n=498\end{array}$ & & $8(2 \%)$ & $\begin{array}{c}474 \\
(95 \%)\end{array}$ & $12(2 \%)$ & & & $\begin{array}{c}2 \\
(<1 \%)\end{array}$ & $\begin{array}{l}2 \\
(<1 \%)\end{array}$ \\
\hline $\begin{array}{l}\text { Rectosigmoid } \\
\mathrm{n}=289\end{array}$ & & & & $\begin{array}{l}280 \\
(97 \%)\end{array}$ & & & $2(1 \%)$ & $7(2 \%)$ \\
\hline $\begin{array}{l}\text { Upper rectum } \\
\mathrm{n}=255\end{array}$ & & & & $\begin{array}{l}245 \\
(96 \%)\end{array}$ & & $2(<1 \%)$ & $\begin{array}{c}1 \\
(<1 \%)\end{array}$ & $7(3 \%)$ \\
\hline $\begin{array}{l}\text { Lower rectum } \\
\mathrm{n}=505\end{array}$ & & & & $\begin{array}{c}177 \\
(35 \%)\end{array}$ & $\begin{array}{c}121 \\
(24 \%)\end{array}$ & $\begin{array}{c}195 \\
(39 \%)\end{array}$ & $\begin{array}{c}2 \\
(<1 \%)\end{array}$ & $\begin{array}{c}10 \\
(2 \%)\end{array}$ \\
\hline
\end{tabular}

APR, abdominoperineal resection; AR, anterior resection; H, Hartmann's procedure; ISR, intersphincteric resection; LHC, left hemicolectomy; PC, partial colectomy; S, sigmoidectomy; TPE, total pelvic exenteration

Table 3. Distribution of metastatic lymph nodes in colorectal cancer patients in this study

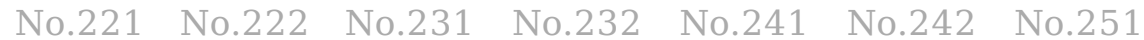

No.252 No.253 LLN

\begin{tabular}{|c|c|c|c|c|c|c|c|c|c|c|}
\hline $\begin{array}{l}\text { Splenic } \\
\text { flexure }\end{array}$ & 5 & 0 & 1 & 0 & & & & & 0 & \\
\hline $\mathrm{pN}+(\mathrm{n}=6)$ & $83.30 \%$ & & $16.70 \%$ & & & & & & & \\
\hline$N(n=11)$ & $45.50 \%$ & & $1.10 \%$ & & & & & & & \\
\hline $\begin{array}{l}\text { Descending } \\
\text { colon }\end{array}$ & 1 & 0 & 9 & 3 & 4 & 0 & 0 & 0 & 0 & \\
\hline $\mathrm{pN}+(\mathrm{n}=17)$ & $5.90 \%$ & & $52.90 \%$ & $17.60 \%$ & $23.50 \%$ & & & & & \\
\hline$N(n=56)$ & $1.80 \%$ & & $16.10 \%$ & $5.30 \%$ & $7.10 \%$ & & & & & \\
\hline $\begin{array}{l}\text { Sigmoid } \\
\text { colon }\end{array}$ & & & 3 & 2 & 164 & 37 & 27 & 32 & 8 & \\
\hline $\begin{array}{c}\mathrm{pN}+ \\
(\mathrm{n}=273)\end{array}$ & & & $1.10 \%$ & $0.70 \%$ & $60.00 \%$ & $13.60 \%$ & $9.90 \%$ & $11.70 \%$ & $2.90 \%$ & \\
\hline $\begin{array}{c}\mathrm{pN}+ \\
(\mathrm{n}=489)\end{array}$ & & & $0.60 \%$ & $0.40 \%$ & $32.90 \%$ & $7.40 \%$ & $5.40 \%$ & $9.40 \%$ & $1.60 \%$ & \\
\hline Rectosigmoid & & & 0 & 2 & 14 & 8 & 108 & 24 & 3 & \\
\hline $\mathrm{N}(\mathrm{n}=159)$ & & & & $1.30 \%$ & $8.80 \%$ & $5.00 \%$ & $67.90 \%$ & $15.10 \%$ & $1.90 \%$ & \\
\hline$N(n=289)$ & & & & $0.70 \%$ & $4.80 \%$ & $2.80 \%$ & $37.40 \%$ & $8.30 \%$ & $1.00 \%$ & \\
\hline $\begin{array}{l}\text { Upper } \\
\text { rectum }\end{array}$ & & & 0 & 1 & 6 & 4 & 95 & 17 & 4 & 8 \\
\hline $\begin{array}{c}\mathrm{pN}+ \\
(\mathrm{n}=135)\end{array}$ & & & & $0.70 \%$ & $4.40 \%$ & $3.00 \%$ & $70.40 \%$ & $12.60 \%$ & $3.00 \%$ & $5.90 \%$ \\
\hline$N(n=255)$ & & & & $0.40 \%$ & $2.40 \%$ & $1.60 \%$ & $37.30 \%$ & $6.70 \%$ & $1.60 \%$ & $3.10 \%$ \\
\hline $\begin{array}{l}\text { Lower } \\
\text { rectum }\end{array}$ & & & 0 & 0 & 11 & 6 & 176 & 35 & 8 & 51 \\
\hline $\begin{array}{c}\mathrm{pN}+ \\
(\mathrm{n}=287)\end{array}$ & & & & & $3.80 \%$ & $2.10 \%$ & $61.30 \%$ & $12.20 \%$ & $2.80 \%$ & $17.80 \%$ \\
\hline $\mathrm{N}(\mathrm{n}=505)$ & & & & & $2.20 \%$ & $1.20 \%$ & $34.90 \%$ & $6.90 \%$ & $1.60 \%$ & $10.00 \%$ \\
\hline
\end{tabular}


LLN, lateral lymph nodes; $\mathrm{n}$, total number of cases; $\mathrm{N}$, percentage of all cases; $\mathrm{pN}+$, percentage of positive lymph nodes

Table 4. Univariable and multivariable analyses of risk factors for overall survival

\begin{tabular}{|c|c|c|c|c|c|c|}
\hline \multirow[t]{2}{*}{ Variable } & \multirow[t]{2}{*}{ Category } & \multirow{2}{*}{$\begin{array}{l}\text { Median overall } \\
\text { survival } \\
\text { (months) }\end{array}$} & \multirow{2}{*}{$\begin{array}{c}\text { Univariable } \\
\text { analysis } \\
p \text {-value }\end{array}$} & \multicolumn{3}{|c|}{ Multivariable analysis } \\
\hline & & & & HR & $95 \%$ CI & $p$-value \\
\hline \multirow[t]{2}{*}{ Year of surgery } & $1995-2017$ & 193 & 0.0002 & Reference & \multirow{3}{*}{$\begin{array}{l}12.922- \\
21.046\end{array}$} & \multirow{3}{*}{$<0.0001$} \\
\hline & 1974-1994 & 180 & & 16.491 & & \\
\hline \multirow[t]{2}{*}{ Sex } & Female & 252 & $<0.0001$ & Reference & & \\
\hline & Male & 175 & & 1.112 & \multirow{2}{*}{$\begin{array}{c}0.964- \\
1.282\end{array}$} & \multirow[t]{2}{*}{0.146} \\
\hline \multirow[t]{2}{*}{ Age (years) } & $<56$ & 337 & $<0.0001$ & Reference & & \\
\hline & $\geq 56$ & 170 & & 1.207 & \multirow{2}{*}{$\begin{array}{l}1.025- \\
1.422\end{array}$} & \multirow[t]{2}{*}{0.024} \\
\hline \multirow[t]{2}{*}{ BMI } & $\leq 21.8$ & 211 & \multirow[t]{2}{*}{0.006} & Reference & & \\
\hline & $>21.8$ & 181 & & 1.075 & $\begin{array}{c}0.935- \\
1.237\end{array}$ & 0.309 \\
\hline Tumor site & $\begin{array}{l}\text { Left-sided } \\
\text { colon } \\
\text { Rectum }\end{array}$ & $\begin{array}{l}208 \\
193\end{array}$ & 0.113 & & & \\
\hline \multirow[t]{2}{*}{ CEA (ng/ml) } & $<5$ & 210 & \multirow[t]{2}{*}{$<0.0001$} & Reference & \multirow{3}{*}{$\begin{array}{l}1.003- \\
1.380\end{array}$} & \multirow{3}{*}{0.046} \\
\hline & $\geq 5$ & 170 & & 1.176 & & \\
\hline \multirow[t]{2}{*}{ Surgery duration (mins) } & $<278$ & 213 & \multirow[t]{2}{*}{0.002} & Reference & & \\
\hline & $\geq 278$ & 179 & & 1.669 & $\begin{array}{c}1.410- \\
1.976\end{array}$ & $<.0001$ \\
\hline \multirow{2}{*}{$\begin{array}{l}\text { Intraoperative bleeding } \\
(\mathrm{ml})\end{array}$} & $<280$ & 229 & \multirow[t]{2}{*}{$<0.0001$} & 0.52 & \multirow[t]{2}{*}{$\begin{array}{l}0.435- \\
0.622\end{array}$} & $<.0001$ \\
\hline & $\geq 280$ & 175 & & Reference & & \\
\hline T category & pT1-pT3 & 212 & $<0.0001$ & 0.862 & $\begin{array}{c}0.737- \\
1.007\end{array}$ & 0.062 \\
\hline & pT4 & 174 & & Reference & & \\
\hline Tumor diameter (mm) & $<45$ & 202 & 0.604 & & & \\
\hline & $\geq 45$ & 192 & & & & \\
\hline Number of metastatic & $<3$ & 208 & $<0.0001$ & Reference & & \\
\hline & $\geq 3$ & 109 & & 1.116 & $\begin{array}{c}0.910- \\
1.378\end{array}$ & 0.292 \\
\hline No.253 LNM & & 200 & 0.002 & 0.431 & $\begin{array}{l}0.187- \\
0.994\end{array}$ & 0.048 \\
\hline & Positive & 57 & & Reference & & \\
\hline Tumor grade & $\mathrm{G} 1, \mathrm{G} 2$ & 202 & 0.001 & Reference & & \\
\hline & G3 & 97 & & 1.165 & $\begin{array}{c}0.843- \\
1.611\end{array}$ & 0.354 \\
\hline Lymphatic invasion & No & 205 & $<0.0001$ & Reference & & \\
\hline & Yes & 149 & & 1.255 & $\begin{array}{c}1.023- \\
1.539\end{array}$ & 0.029 \\
\hline Venous invasion & No & 208 & $<0.0001$ & Reference & & \\
\hline & Yes & 119 & & 1.199 & $\begin{array}{c}0.968- \\
1.485\end{array}$ & 0.096 \\
\hline Perineural invasion & No & 202 & 0.423 & & & \\
\hline & Yes & 200 & & & & \\
\hline Adjuvant therapy & Yes & 212 & 0.049 & 0.84 & $\begin{array}{c}0.723- \\
0.975\end{array}$ & 0.022 \\
\hline & No & 174 & & Reference & & \\
\hline Postoperative & Grade I, II & 200 & 0.073 & & & \\
\hline $\begin{array}{l}\text { (Clavien-Dind o } \\
\text { Classification) }\end{array}$ & $\begin{array}{c}\text { Grade III, } \\
\text { IV }\end{array}$ & 149 & & & & \\
\hline
\end{tabular}


BMI, body mass index; CI, confidence interval; HR, hazard ratio; LNM, lymph node metastasis

Missing information: CEA: $\mathrm{n}=33$ (2.0\%); BMI: $\mathrm{n}=22$ (1.4\%); Left-sided colon: transverse (splenic flexure) colon to rectosigmoid colon; surgery time: $\mathrm{n}=42$ (2.6\%); intraoperative bleeding: $\mathrm{n}=49$ (3.0\%); tumor diameter: $\mathrm{n}=9$ (0.5\%); lymphatic invasion: $\mathrm{n}=4(0.2 \%)$; venous invasion: $\mathrm{n}=6(0.3 \%)$; perineural invasion: $\mathrm{n}=11(0.7 \%)$; adjuvant therapy: $\mathrm{n}=187(11.6 \%)$

Table 5. Univariable and multivariable analyses of No.253 lymph node metastasis positivity and site of recurrence

\begin{tabular}{lccccc} 
Recurrence site & \multicolumn{2}{c}{ No.253 LNM } & Univariate & \multicolumn{2}{c}{ Logistic regression } \\
& Positive & Negative & $p$-value & Odds ratio & $p$-value \\
\hline Liver & 2 & 125 & 0.882 & & - \\
\hline Lung & 6 & 108 & 0.001 & 3.765 & 0.013 \\
\hline Local & 2 & 70 & 0.322 & & - \\
\hline Lymph node & 2 & 27 & 0.012 & 3.205 & 0.156 \\
\hline Peritoneum & 1 & 28 & 0.354 & & - \\
\hline Bone & 1 & 13 & 0.07 & 2.985 & 0.328 \\
\hline Brain & 0 & 5 & 0.788 & & -
\end{tabular}

\section{Figures}




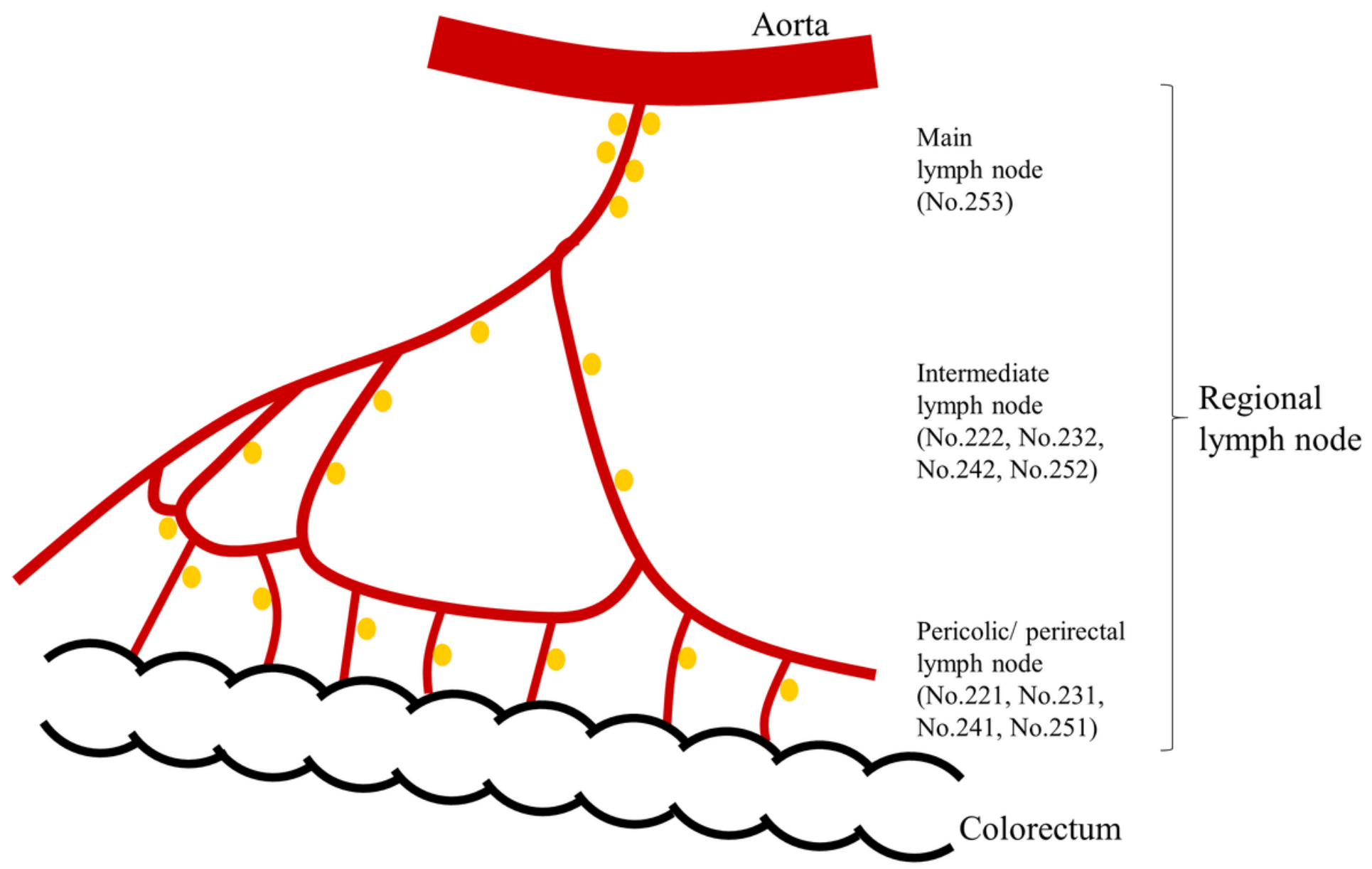

Figure 1

Relationship between regional LNs and blood vessels. No.221, No.231, No.241, and No.251 LNs are pericolic/perirectal LNs of the transverse colon, descending colon, sigmoid colon, and rectum. No.232, No.242, and No.252 LNs are intermediate LNs of left colic nodes, sigmoid colic nodes, and inferior mesenteric trunk nodes. 


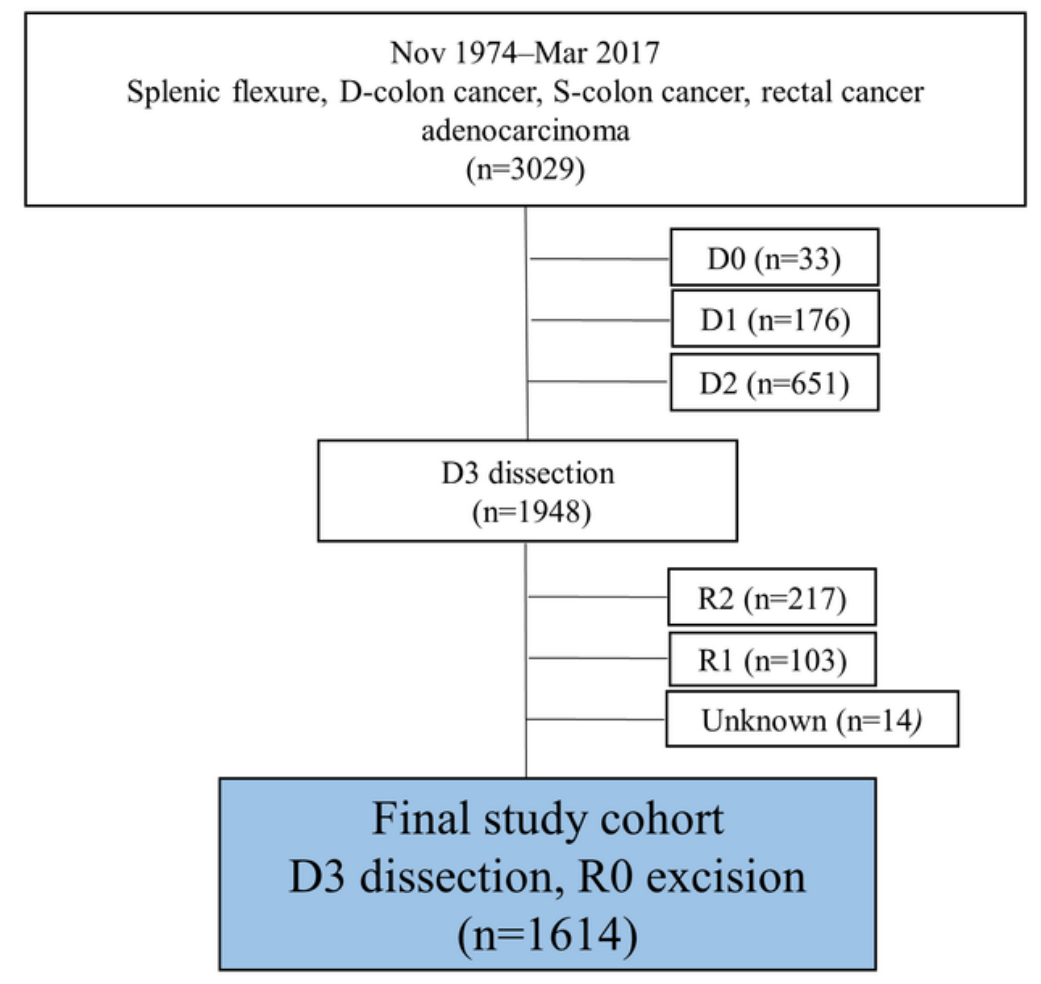

\section{Figure 2}

Flow chart of the study cohort. After excluding patients with D0 resection $(n=33)$, D1 resection $(n=176)$, D2 resection $(n=651)$, R2 resection $(n=217)$, R1 resection $(n=103)$, and unknown $(n=14)$ from the initial 3,029 patients diagnosed with colorectal cancer, the final study population consisted of 1,614 patients. 


\section{Overall survival}

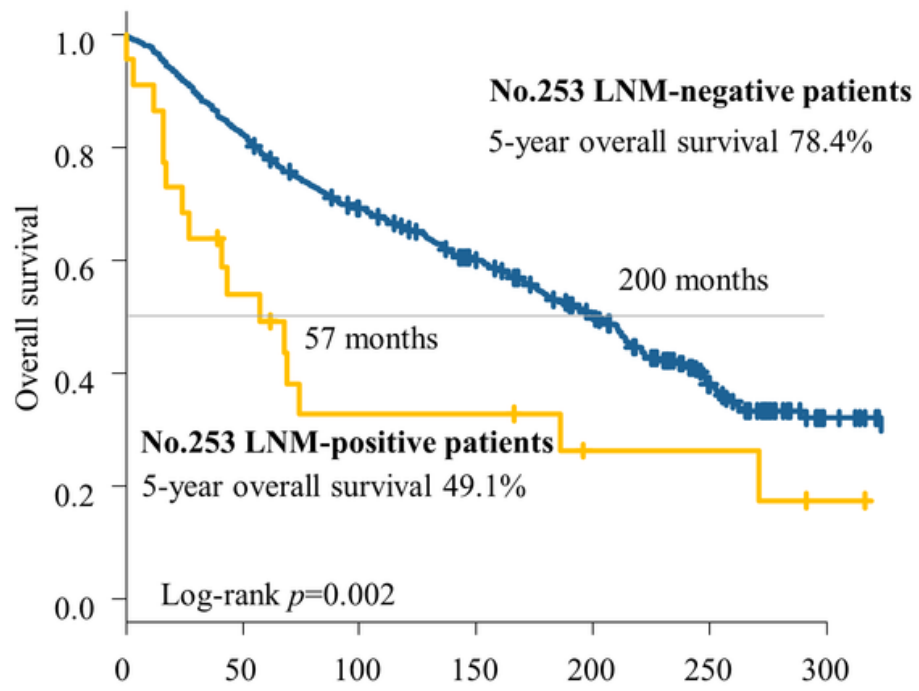

Disease-free survival

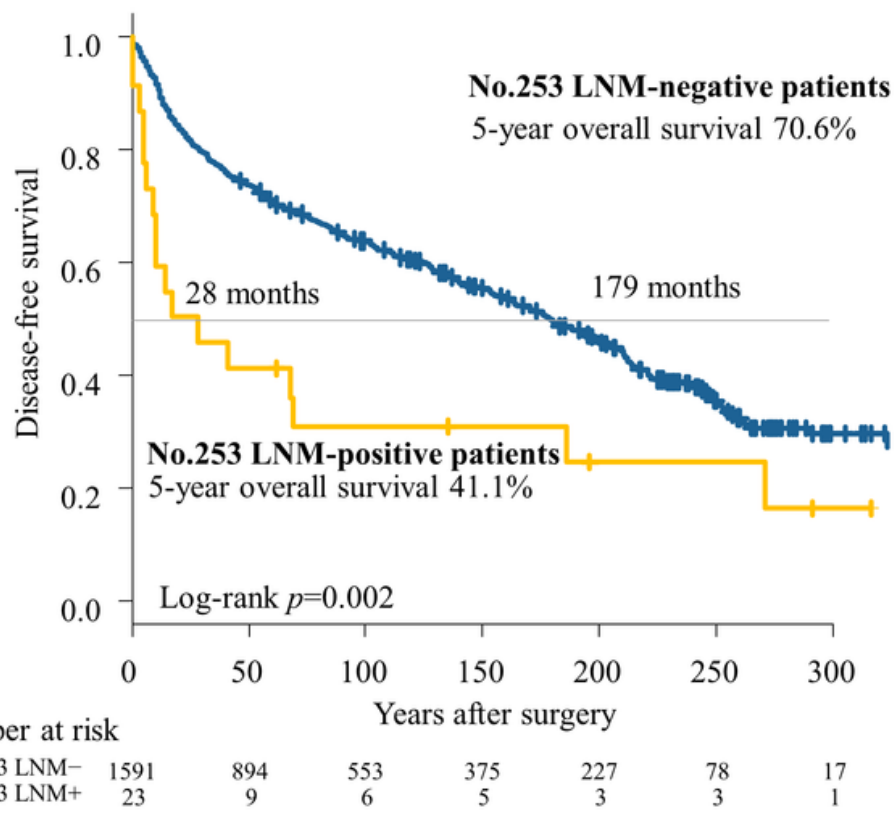

\section{Figure 3}

Comparison of the long-term outcomes of No.253 LNM-positive and No.253 LNM-negative patients. a. Overall survival. b. Disease-free survival. LNM, lymph node metastasis 